\title{
PERAN KOMITMEN ORGANISASIONAL SEBAGAI VARIABEL PEMEDIASI ANTARA STRES KERJA DENGAN TURNOVER INTENTION KARYAWAN
}

\author{
I Komang Dedi Sanjaya ${ }^{1}$ \\ Anak Agung Ayu Sriathi ${ }^{2}$ \\ ${ }^{1,2}$ Fakultas Ekonomi dan Bisnis Universitas Udayana (Unud), Bali, Indonesia \\ email: dedylepang25@gmail.com
}

\begin{abstract}
ABSTRAK
Tujuan dari penelitian ini adalah untuk menjelaskan peran komitmen organisasional sebagai variabel pemediasi antara stres kerja dengan turnover intention. Penelitian ini dilakukan di hotel Wyndham Taman Sari Jivva Bali di Kabupaten Klungkung. Jumlah sampel dalam penelitian ini sebanyak 63 orang karyawan, melalui rumus slovin. Pengumpulan data dilakukan melalui penyebaran kuesioner, wawancara, dan observasi. Teknik analisis yang digunakan adalah analisis jalur (path analysis). Berdasarkan hasil penelitian ditemukan bahwa stres kerja berpengaruh negatif dan signifikan terhadap komitmen organisasional. Komitmen organisasional berpengaruh negatif dan signifikan terhadap turnover intention. Stres kerja berpengaruh positif dan signifikan terhadap turnover intention. Komitmen organisasional dapat memediasi pengaruh stres kerja terhadap turnover intention. Manajemen sebaiknya memperhatikan kejelasan informasi mengenai jenjang karir yang didapat karyawan dimasa depan agar karyawan tidak mengalami stres kerja akibat dari tidak jelasnya jenjang karir yang didapat dan juga manajemen perlu memperhatikan keterlibatan karyawan di dalam perusahaan.
\end{abstract}

Kata Kunci: turnover intention, stres kerja, komitmen organisasional

\section{ABSTRACT}

The purpose of this study is to explain the role of organizational commitment as a mediating variable between work stress and turnover intention. This research was conducted at the Wyndham Taman Sari Jivva Bali hotel in Klungkung Regency. The number of samples in this study were 63 employees, through the Slovin formula. Data collection is carried out through questionnaires, interviews, and observations. The analysis technique used is path analysis. Based on the results of the study found that work stress has a negative and significant effect on organizational commitment. Organizational commitment has a negative and significant effect on turnover intention. Job stress has a positive and significant effect on turnover intention. Organizational commitment can mediate the effect of work stress on turnover intention. Management should pay attention to the clarity of information regarding career paths obtained by employees in the future so that employees do not experience work stress due to unclear career paths obtained and also management needs to pay attention to employee involvement in the company.

Keywords: turnover intention, work stress, organizational commitment 


\section{PENDAHULUAN}

Bali sebagai destinasi wisata yang memiliki banyak objek wisata menyebabkan tumbuhnya berbagai bisnis akomodasi yang tentunya membutuhkan sumber daya manusia (SDM) yang berkualitas untuk mencapai visi, misi, dan tujuan dari bisnis tersebut. Setiap perusahaan memiliki kewajiban untuk menjaga karyawannya agar tidak meninggalkan perusahaan, sehingga karyawan yang memiliki pengaruh besar terhadap perusahaan tidak meninggalkan perusahaan. Turnover intention dapat juga diartikan sebagai niat karyawan untuk berpindah dari suatu perusahaan atau keluar dari perusahaan, baik dalam bentuk pemberhentian atau pengunduran diri (Putri Rarasanti dan Suana, 2016).

Sumber daya manusia dalam hal ini karyawan berperan besar dalam mendukung pencapaian tujuan perusahaan melalui kinerja yang dikontribusikan dengan penyelesaian tugas - tugas yang dibebankan (Damayanthi dan Sintaasih, 2016). Setiap perusahaan memiliki kewajiban untuk menjaga karyawannya agar tidak meninggalkan perusahaan, sehingga karyawan yang memiliki pengaruh besar terhadap perusahaan tidak meninggalkan perusahaan. Turnover intention dapat juga diartikan sebagai niat karyawan untuk berpindah dari suatu perusahaan atau keluar dari perusahaan, baik dalam bentuk pemberhentian atau pengunduran diri (Putri dan Suana, 2016).

Turnover intention memiliki dampak negatif pada perusahaan selain dapat menciptakan ketidakstabilan terhadap kondisi tenaga kerja, turnover intention juga dapat menurunkan produktivitas perusahaan dan menimbulkan suasana kerja yang tidak kondusif (Widodo, 2015). Karyawan yang ingin meninggalkan perusahaan biasanya dapat diakibatkan oleh faktor dari dalam karyawan tersebut. Faktor-faktor turnover intention yang menyebabkan karyawan memiliki niat untuk meninggalkan perusahaan diantaranya adalah stres kerja, kepuasan kerja, budaya organisasi, dan komitmen organisasional (Johartono dan Widuri, 2014). Dalam penelitian ini menggunakan 2 faktor turnover intention yaitu stres kerja dan komitmen organisasional, dimana faktor ini akan digunakan sebagai variabel $\mathrm{X}$ (bebas) dan $\mathrm{Z}$ (mediasi). Stres kerja perlu diperhatikan oleh perusahaan karena stres kerja merupakan penentu optimal atau tidaknya output karyawan yang dihasilkan baik yang berupa barang maupun jasa (Hlatywayo et al., 2014). Selanjutnya Turnover intention dapat berkurang apabila komitmen organisasional tinggi disuatu perusahaan (Saqib et al., 2014).

Karyawan yang ingin meninggalkan perusahaan biasanya dapat diakibatkan oleh faktor dari dalam karyawan tersebut. Faktor-faktor turnover intention yang menyebabkan karyawan memiliki niat untuk meninggalkan perusahaan diantaranya adalah stres kerja, kepuasan kerja, budaya organisasi, dan komitmen organisasional (Johartono dan Widuri, 2014). Dalam penelitian ini menggunakan 2 faktor turnover intention yaitu stres kerja dan komitmen organisasional, dimana faktor ini akan digunakan sebagai variabel $\mathrm{X}$ (bebas) dan Z (mediasi).

Stres merupakan suatu proses psikologis yang tidak menyenangkan yang terjadi sebagai tanggapan terhadap tekanan lingkungan (Robbins dan Judge, 2015: 433). Stres kerja diartikan sebagai sebuah keadaan yang membuat seseorang merasa tertekan dimana tekanan ini berada di luar batas kemampuannya, yang mana jika berlanjut terjadi tanpa adanya solusi dan tidak segera ditanggulangi, akan 
berdampak terhadap kesehatan orang yang menderita stres tersebut (Fahmi, 2016:256). Stres kerja dan turnover intention memiliki pengaruh yang berbanding lurus, hal ini menunjukkan bahwa semakin tinggi tingkat stres kerja yang dialami oleh karyawan maka akan cenderung meningkatkan turnover intention (Rismawan dkk., 2015). Stres kerja perlu diperhatikan oleh perusahaan karena stres kerja merupakan penentu optimal atau tidaknya output karyawan yang dihasilkan baik yang berupa barang maupun jasa (Hlatywayo et al., 2014).

Penelitian ini dilakukan pada Wyndham Taman Sari Jivva Resort Bali karena resort tersebut merupakan salah satu resort yang terbesar di kabupaten Klungkung, selain itu fasilitas dari resort ini cukup lengkap mulai dari restaurant, kolam renang yang menghadap langsung kepantai, tempat pertunjukan seni dan budaya, fasilitas spa dan tempat gym sampai dengan beach club (https://wyndhamjivvabali.com/, 2019). Wyndham Taman Sari Jivva Resort Bali telah beroperasi dari 25 November 2016 dan selama 3 tahun beroperasi sudah mengalami beberapa masalah salah satunya yaitu adalah turnover, seperti yang ditunjukkan pada Tabel 1 .

Wyndham Taman Sari Jivva Resort Bali merupakan salah satu bisnis yang bergerak dibidang perhotelan. Wyndham Taman Sari Jivva Resort Bali berada di kabupaten Klungkung tepatnya di Jl. Subak Lepang No. 16, desa Takmung, kecamatan Banjarangkan, Kabupaten Klungkung, Bali, Indonesia. Pemilik Wyndham Taman Sari Jivva Resort Bali adalah ibu Rieta Amelia dibawah naungan PT. Wyndham Hotel Management. Dalam pengelolaan Wyndham Taman Sari Jivva Resort Bali dibutuhkan SDM yang berkualitas serta memiliki ketekunan dalam bekerja sehingga Wyndham Taman Sari Jivva Resort Bali dapat bersaing dengan bisnis-bisnis perhotelan lainnya yang ada di Bali. Alasan dipilihnya Wyndham Taman Sari Jivva Resort Bali karena resort tersebut merupkan salah satu resort yang terbesar di kabupaten Klungkung, selain itu fasilitas dari resort ini cukup lengkap mulai dari restaurant, kolam renang yang menghadap langsung kepantai, tempat pertunjukan seni dan budaya, fasilitas spa dan tempat gym sampai dengan beach club.

Wyndham Taman Sari Jivva Resort Bali telah beroperasi dari 25 November 2016. Selama 3 tahun beroperasi Wyndham Taman Sari Jivva Resort Bali mengalami beberapa masalah salah satunya yaitu adalah turnover. Berikut data turnover periode September 2018 - September 2019 dari Wyndham Taman Sari Jivva Resort Bali. Pada awal periode jumlah keseluruhan karyawan Wyndham Taman Sari Jivva Resort Bali adalah 176 karyawan dan pada akhir periode jumlah karyawan sebanyak 172. Dapat diuraikan bahwa dalam Tabel 1. karyawan dibedakan menjadi dua yaitu karyawan dengan turnover dan new hire, dimana selanjutnya diuraikan lagi berdasarkan jenis kelamain karyawan yaitu laki-laki dan perempuan. Dari uraian diatas sebanyak 25 karyawan laki-laki dan 11 karyawan perempuan melakukan turnover pada periode September 2018 - 2019. Data tersebut juga menjelaskan jumlah karyawan masuk (new hire) yaitu sebanyak 19 karyawan laki-laki dan 12 karyawan perempuan periode September 2018 -2019. Dari data tersebut dapat disimpulkan bahwa jumlah keseluruhan karyawan yang melakukan turnover adalah 36 karyawan sedangkan karyawan yang masuk ke perusahaan (new hire) sebanyak 31 orang. 
Tabel 1.

Data Turnover Wyndham Taman Sari Jivva Resor (September 2018 - 2019)

\begin{tabular}{|c|c|c|c|c|}
\hline \multirow[t]{2}{*}{ BULAN } & \multicolumn{2}{|c|}{ MASUK } & \multicolumn{2}{|c|}{ KELUAR } \\
\hline & Laki-laki & Perempuan & Laki-laki & Perempuan \\
\hline September 2018 & - & 2 & - & - \\
\hline Oktober 2018 & 4 & 1 & - & - \\
\hline November 2018 & 3 & - & 3 & 3 \\
\hline Desember 2018 & 1 & 1 & 1 & - \\
\hline Januari 2019 & 4 & 2 & 2 & 1 \\
\hline Februari 2019 & 1 & - & 4 & - \\
\hline Maret 2019 & 1 & 1 & - & - \\
\hline April 2019 & 4 & - & - & - \\
\hline Mei 2019 & 1 & 1 & 3 & 2 \\
\hline Juni 2019 & 3 & 2 & 2 & 2 \\
\hline Juli 2019 & - & - & 2 & 1 \\
\hline Agustus 2019 & 2 & - & 1 & 2 \\
\hline September 2019 & 1 & 1 & 2 & 1 \\
\hline Total & 25 & 11 & 19 & 12 \\
\hline Total Keseluruhan & \multicolumn{2}{|c|}{36} & \multicolumn{2}{|c|}{31} \\
\hline
\end{tabular}

Sumber: HRD Wyndham Taman Sari Jivva Resort Bali, 2019

Menurut Gillies (1989) tingkat perputaran karyawan dikatakan normal apabila berada dalam kisaran 5-10 persen per tahun. Jika tingkat perputaran karyawan lebih dari 10 persen per tahun maka turnover karyawan dikatakan tinggi. Pada periode bulan September 2018-September 2019 turnover rate di Wyndham Taman Sari Jivva Resort Bali sebesar 20 persen. Hal ini menunjukkan bahwa tingkat turnover di Wyndham Taman Sari Jivva Resort Bali tinggi. Turnover yang tinggi pada perusahaan mengindentifikasi keinginan karyawan keluar perusahaan juga tinggi.

Berdasarkan pra riset melalui metode wawancara terhadap 2 karyawan front office, 2 karyawan housekeeping dan 1 karyawan kitchen, menyatakan bahwa terdapat beberapa faktor yang menyebabkan tingginya turnover. Faktor pertama adalah stres kerja akibat dari karyawan menerima beban kerja diluar dari apa yang diharapkan sebelumnya oleh karyawan. Hal ini biasanya disebabkan karena tingginya tingkat hunian kamar (occupancy) yang tinggi tidak sesuai dengan jumlah karyawan yang bekerja pada shift tersebut. Hubungan antar karyawan dan lingkungan kerja yang kurang baik juga dapat meningkatkan turnover intention. Hubungan yang kurang baik antar karyawan menyebabkan karyawan merasa terganggu dalam menyelesaikan tugas karena kurang mendapat dukungan dari karyawan lain. Hubungan antar karyawan merupakan salah satu indikator stres kerja yang dapat meningkatkan turnover intention.

Stres kerja diakibatkan oleh stressor didalam Wyndham Taman Sari Jivva Resort Bali salah satunya akibat dari ketidak adilan beban kerja yang diterima dari setiap karyawan. Beban kerja yang besar cenderung akan diberikan kepada karyawan yang memiliki masa kerja atau pengalaman yang kurang. Karyawan akan mengalami stres kerja akibat dari beban kerja yang didapatkan dari atasan tidak sesuai dengan kemampuan yang dimiliki karyawan tersebut. Stressor lain yang menyebabkan karyawan stres adalah atasan yang menekan karyawan terlalu keras setiap memberikan pekerjaan kepada karyawan. Karyawan akan merasa tertekan 
didalam menyelesaikan tugas atau pekerjaan yang diberikan oleh atasan sehingga terkadang akan menyebabkan pekerjaan yang dikerjakan karyawan tidak sesuai dengan apa yang diperintahkan atasan. Hal ini akan menyebabkan karyawan mengalami stres kerja dan akan meningkatkan keinginan karyawan untuk melakukan turnover intention.

Stres kerja juga diakibatkan oleh lingkungan kerja fisik dimana salah satunya mengenai tentang lokasi perusahaan yang dapat mempengaruhi karyawan. Wyndham Taman Sari Jivva Resort Bali berada di pesisir pantai Lepang. Pantai Lepang merupakan salah satu pantai yang pernah mengalami abrasi, hingga air laut masuk ke wilayah hotel khususnya beach club yang tepat berada di bibir pantai Lepang. Abrasi tersebut juga menyebabkan beberapa kerusakan seperti pagar yang membatasi pantai dengan hotel rusak, beberapa fasilitas di beach club mengalami kerusakan. Hal ini menyebabkan keresahan pada karyawan Wyndham Taman Sari Jivva Resort Bali dan meningkatkan keinginan karyawan meninggalkan perusahaan (turnover intention).

Berdasarkan pra riset dari hasil wawancara dengan staff dari human resources develepoment (HRD) Wyndham Taman Sari Jivva Resort Bali menyatakan bahwa karyawan yang sering melakukan turnover berada pada departemen Housekeeping, food and baverage sevices, kitchen, engineering and gardener, dan sales and marketing. Hal tersebut berdasarkan tabel berikut:

Tabel 2.

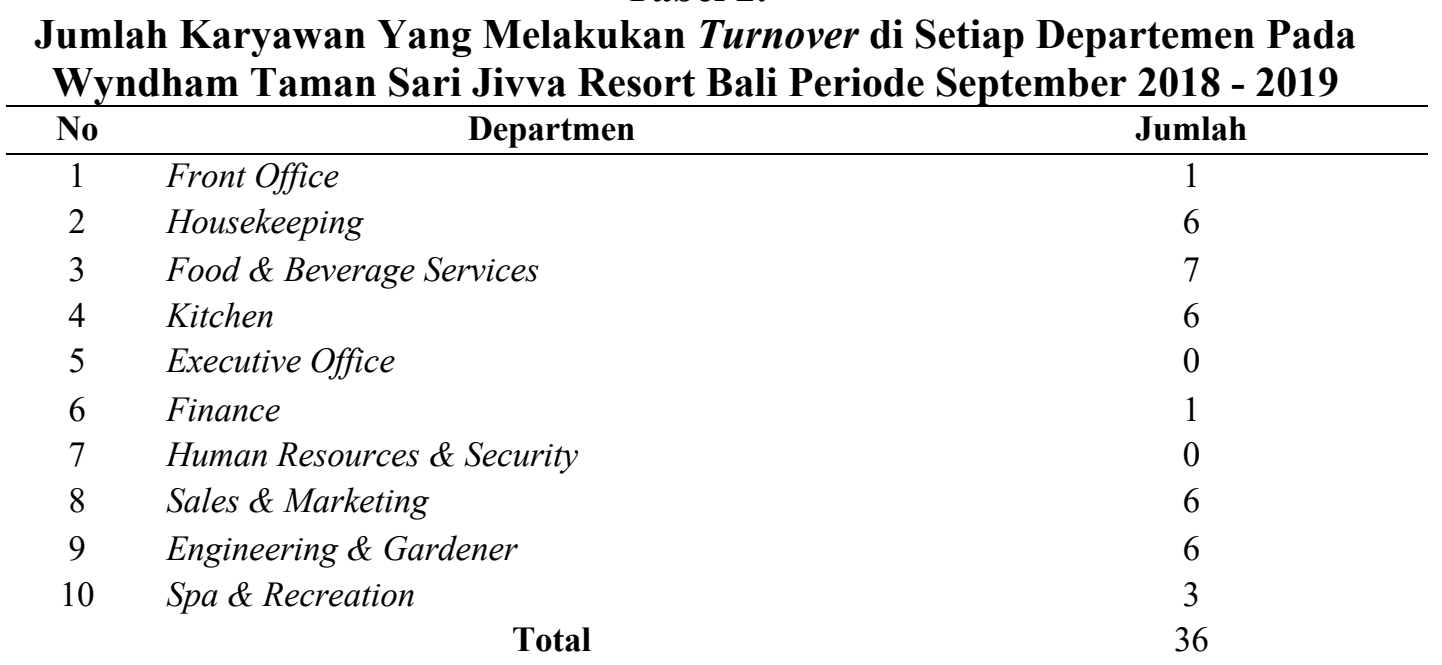

Sumber: HRD Wyndham Taman Sari Jivva Resort Bali, 2019

Staff dari HRD Wyndham Taman Sari Jivva Resort Bali juga menyatakan bahwa sering melakukan pengawasan dan mengevaluasi kinerja karyawan, namun jarang melakukan training kepada karyawan yang sudah bekerja di Wyndham Taman Sari Jivva Resort Bali. Hal tersebut untuk menekan biaya yang dikeluarkan perusahaan dalam manajemen sumber daya manusia di Wyndham Taman Sari Jivva Resort Bali. Training yang dilakukan kepada karyawan yang sudah ada di Wyndham Taman Sari Jivva Resort Bali akan memakan waktu yang dapat mengganggu kinerja karyawan dalam menyelesaikan tugas yang diberikan. HRD Wyndham Taman Sari Jivva Resort Bali menyatakan bahwa training terjadi dari 
pembelajaran yang diberikan oleh senior yang memiliki pengalaman lebih banyak dari karyawan lainnya.

Staff tersebut juga menyatakan bahwa banyak karyawan yang memiliki ambisi untuk mendapatkan jenjang karir yang tinggi, namun tidak semua karyawan dapat terpenuhi keinginannya, dikarenakan jenjang karir yang diinginkan oleh karyawan sudah terisi. Karyawan yang ingin meningkatkan jenjang karir harus memiliki kemampuan sesuai dengan jenjang karir yang diinginkannya. Karyawan yang tidak terpenuhi keinginannya dapat meningkatkan turnover intention dengan harapan mendapatkan jenjang karir yang lebih baik diperusahaan lain, oleh karena hal tersebut variabel stres kerja dapat mempengaruhi komitmen organisasional dan menyebabkan turnover intention.

HRD Wyndham Taman Sari Jivva Resort Bali juga menyatakan bahwa banyak karyawan yang memiliki ambisi untuk mendapatkan jenjang karir yang tinggi, namun tidak semua karyawan dapat terpenuhi keinginannya, dikarenakan jenjang karir yang diinginkan oleh karyawan sudah terisi. Karyawan yang ingin meningkatkan jenjang karir harus memiliki kemampuan sesuai dengan jenjang karir yang diinginkannya. Karyawan yang tidak terpenuhi keinginannya dapat meningkatkan turnover intention dengan harapan mendapatkan jenjang karir yang lebih baik diperusahaan lain, oleh karena hal tersebut variabel stres kerja dapat mempengaruhi komitmen organisasional dan menyebabkan turnover intention.

Turnover intention merupakan niat karyawan untuk berpindah dari suatu perusahaan atau keluar dari perusahaan, baik dalam bentuk pemberhentian atau pengunduran diri (Putri Rarasanti dan Suana, 2016). Stres kerja diartikan sebagai sebuah keadaan yang membuat seseorang merasa tertekan dimana tekanan ini berada di luar batas kemampuannya, yang mana jika berlanjut terjadi tanpa adanya solusi dan tidak segera ditanggulangi, akan berdampak terhadap kesehatan orang yang menderita stres tersebut (Fahmi, 2016:256).

Suhada dkk. (2015) menyatakan komitmen organisasional merupakan suatu keadaan dimana karyawan merasa terikat terhadap suatu perusahaan yang cenderung menimbulkan sikap positif dari karyawan kepada perusahaan.

Berdasarkan telaah dan kajian penelitian terdahulu, maka dapat disusun hipotesis sebagai berikut:

$\mathrm{H}_{1}$ : Stres kerja berpengaruh negatif dan signifikan terhadap komitmen organisasional pada karyawan Wyndham Taman Sari Jivva Resort Bali.

$\mathrm{H}_{2}$ : Komitmen organisasional berpengaruh negatif dan signifikan terhadap turnover intention pada karyawan di Wyndham Taman Sari Jivva Resort Bali.

$\mathrm{H}_{3}$ : Stres kerja berpengaruh positif dan signifikan terhadap turnover intention pada karyawan Wyndham Taman Sari Jivva Resort Bali.

$\mathrm{H}_{4}$ : Stres kerja berpengaruh negatif dan signifikan terhadap turnover intention melalui mediasi komitmen organisasional pada karyawan Wyndham Taman Sari Jivva Resort Bali.

Berdasarkan kajian pustaka yang telah diuraikan stres kerja memiliki pengaruh terhadap komitmen organisasional. Semakin tinggi stres kerja yang dialami karyawan maka komitmen organisasional karyawan akan menurun. Hal ini juga dipertegas dari penelitian yang dilakukan oleh Velnampy dan Aravinthan (2013), Putra dan Ardana (2018), Rismawan dkk. (2015), Irwanto dkk. (2016), 
Pranata dan Netra (2019), Harun et al. (2017), Addae et al. (2012), Michael dan Court (2009) dan Lee (2000) yang menyatakan bahwa stres kerja berpengaruh negatif terhadap stres kerja. Komitmen organisasaional juga dapat mempengaruhi turnover intention. Semakin tinggi komitmen organisasional karyawan maka semakin rendah turnover intention karyawan disuatu perusahaan. Hal tersebut senada dengan penelitian yang dilakukan sebelumnya oleh Pranata dan Netra (2019), Matti (2014), Saqib et al. (2014), Johartono dan Widuri (2014), Putra dan Wibawa (2014), Taing et al. (2011), Clayton dan Hutchinson (2002), Mathieu dan Zajac (1990) yang menyatakan bahwa komitmen organisasional berpengaruh negatif terhadap turnover intention.

Stres kerja dapat mempengaruhi turnover intention karyawan disuatu perusahaan. Semakin tinggi stres kerja maka semakin tinggi turnover intention karyawan di perusahaan tersebut. Penelitian sebelumnya yang dilakukan oleh Parvaiz et al. (2015), Rai (2015), Mitchell et al. (2014), Ketabchi dan Hazraty (2015), Siddiqui dan Jamil (2015), Yuda dan Ardana (2017), Shih-Tse Wang (2014) menyatakan bahwa semakin tinggi stres kerja maka turnover intention disuatu perusahaan juga akan menningkat. Komitmen organisasional dapat menjadi variabel pemediasi antara stres kerja dan turnover intention. Hal ini juga disebutkan pada penelitian sebelumnya oleh Akehurst et al. (2009), Rismawan dkk. (2015), Irwanto dkk. (2016), Putra dan Ardana (2018), Pranata dan Netra (2019), MingShiun dan Shin-Lung (2019), Serinikli (2019), yang menyatakan bahwa variabel komitmen organisasional mampu memediasi pengaruh stres kerja terhadap turnover intention. Kerangka konseptual berdasarkan yang telah diuraikan diatas adalah sebagai berikut:

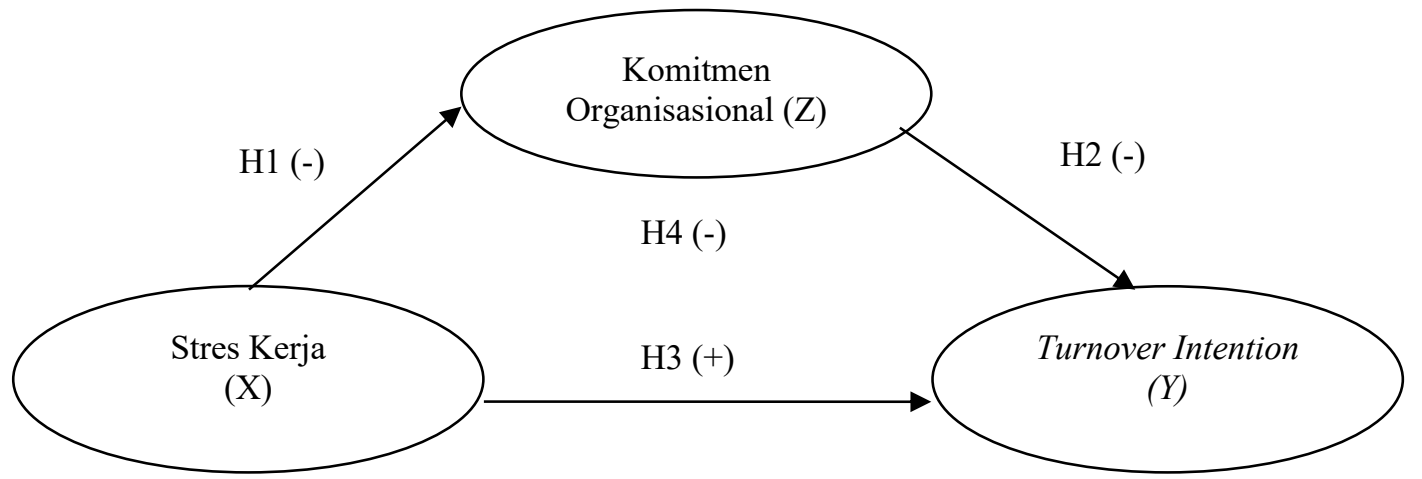

\section{Gambar 1. Kerangka Konseptual}

Sumber : kajian penelitian terdahulu

\section{METODE PENELITIAN}

Desain penelitian ini yaitu desain penelitian klausalitas. Desain penelitian klausalitas adalah desain penelitian yang disusun untuk meneliti kemungkinan adanya hubungan sebab-akibat antarvariabel yakni untuk mengetahui hubungan variabel stres kerja, komitmen organisasional terhadap turnover intention.

Penelitian ini dilakukan di Wyndham Taman Sari Jivva Resort Bali. Resor ini bergerak dibidang perhotelan. Resor ini beralamat di kabupaten Klungkung tepatnya di J1. Subak Lepang No. 16, desa Takmung, kecamatan Banjarangkan, 
Kabupaten Klungkung, Bali, Indonesia. Lokasi ini dipilih karena perusahaan terindikasi mengalami turnover terhadap karyawan. Variabel yang diteliti dalam penelitian ini terdapat 3 jenis variabel diantaranya variabel eksogen yaitu stres kerja $(\mathrm{X})$, variabel endogen yaitu turnover intention (Y) dan variabel mediasi yaitu komitmen organisasional $(\mathrm{Z})$ yang masing-masing diukur menggunakan indikator sebagai berikut:

Tabel 3.

Indikator Variabel Penelitian

\begin{tabular}{|c|c|c|c|}
\hline No & Variabel & Indikator & Sumber \\
\hline 1. & $\begin{array}{c}\text { Turnover } \\
\text { Intention }(\mathrm{Y})\end{array}$ & $\begin{array}{l}\text { 1) Keinginan untuk mencari perusahaan lain sesuai dengan } \\
\text { keahlian yang dimiliki } \\
\text { 2) Keinginan untuk mencari pekerjaan baru pada bidang } \\
\text { yang berbeda diperusahaan lain } \\
\text { 3) Keinginan untuk meningkatkan jenjang karir } \\
\text { diperusahaan lain }\end{array}$ & $\begin{array}{l}\text { (Widjaja } \\
\text { dkk. } \\
\text { 2008:75) }\end{array}$ \\
\hline 2. & $\begin{array}{c}\text { Stres Kerja } \\
\text { (X) }\end{array}$ & $\begin{array}{l}\text { 1) Faktor intrinsik pekerjaan } \\
\text { 2) Pengembangan karir } \\
\text { 3) Hubungan di tempat kerja }\end{array}$ & $\begin{array}{l}\text { (Salleh } \\
\text { et al. } \\
\text { 2008) }\end{array}$ \\
\hline 3. & $\begin{array}{c}\text { Komitmen } \\
\text { Organisasional } \\
(\mathrm{Z})\end{array}$ & $\begin{array}{l}\text { 1) Komitmen afektif } \\
\text { 2) Komitmen berkelanjutan } \\
\text { 3) Komitmen normatif }\end{array}$ & $\begin{array}{c}\text { (Shaleh, } \\
\text { 2018) }\end{array}$ \\
\hline
\end{tabular}

Sumber: Kajian penelitian sebelumnya, 2020

Populasi dalam penelitian ini adalah seluruh karyawan Wyndham Taman Sari Jivva Resort Bali yang berjumlah 172 karyawan. Metode penentuan sampel yaitu menggunakan Simple Random Sampling dan jumlah sampeng dihitung menggunakan rumus Slovin, sehingga jumlah sampel yang didapat adalah 63,23 yang dibulatkan menjadi 63 responden. Sampel yang digunakan dalam penelitian ini berasal dari karyawan tetap dan karyawan kontrak Wyndham Taman Sari Jivva Resort Bali. Selanjutnya data dikumpulkan dengan kuesioner. Data yang diperoleh selama pengumpulan data dilapangan dianalisis dengan menggunakan statistik deskriptif, analisis jalur, dan uji sobel.

\section{HASIL DAN PEMBAHASAN}

Penelitian ini menggunakan data primer yang didapat dari kuisioner yang dijawab oleh responden Wyndham Taman Sari Jivva Resort Bali. Jumlah responden yang digunakan dalam penelitian ini sebanyak 63 orang. Namun sebanyak 4 kuisioner atau sebesar 7,9 persen tidak kembali sehingga jumlah responden yang berpartisipasi dalam penelitian ini sebanyak 59 responden. Uraian tentang karakteristik responden menyangkut beberapa aspek yaitu jenis kelamin, usia, dan pendidikan terakhir. Karakteristik responden diuraikan pada Tabel 4.

Tabel 4. menunjukkan sebagian besar karyawan Wyndham Taman Sari Jivva Resort Bali mempekerjakan tenaga laki-laki. Hal ini menunjukan sebagian besar karyawan yang diperlukan untuk bidangnya adalah tenaga kerja laki-laki, hal ini dikarenakan pekerjaan di Wyndham Taman Sari Jivva Resort Bali memerlukan tenaga yang cukup, disiplin, dan keuletan terutama di bidang housekeeping, engineering and gardener, dan kitchen karena laki-laki lebih mampu berperan 
dalam menjalankan tugas perusahaan yang berkaitan dengan fisik. Kemudian data menunjukkan menunjukan bahwa sebagian besar responden berusia di antara 20-30 tahun dengan persentase sebesar 50,85 persen, selanjutnya berada dikisaran usia 31-40 tahun sebesar 44,06 persen, sedangkan untuk kelompok usia terendah yaitu pada usia 41-50 tahun dengan persentase 5,09 persen. Hal ini dikarenakan pada usia 20-30 adalah usia produktif untuk bekerja. Selanjutnya data menunjukan pekerjaan di Wyndham Taman Sari Jivva Resort Bali pada bidang operasionalnya lebih diutamakan lulusan Diploma 3 (D3), karena pendidikan Diploma 3 (D3) memiliki teori yang mencukupi, selain itu Diploma 3 (D3) juga sudah mendapatkan kemampuan karena program-program training yang diikuti sebelum mempraktekkannya didunia kerja

Tabel 4.

Karakteristik Responden Wyndham Taman Sari Jivva Resort Bali

\begin{tabular}{ccccc}
\hline No & & Kriteria & $\begin{array}{c}\text { Jumlah Responden } \\
\text { (Orang) }\end{array}$ & $\begin{array}{c}\text { Persentase Responden } \\
\text { (\%) }\end{array}$ \\
\hline 1 & Jenis & Laki-Laki & 43 & 72,88 \\
2 & Kelamin & Perempuan & 16 & 27,12 \\
& & Total & $\mathbf{5 9}$ & $\mathbf{1 0 0}$ \\
1 & & $20-30$ tahun & 30 & 50,85 \\
2 & Usia & $31-40$ tahun & 26 & 44,06 \\
3 & & $41-50$ tahun & 3 & 5,09 \\
& & Total & $\mathbf{5 9}$ & $\mathbf{1 0 0}$ \\
1 & & SMA / SMK & 9 & 15,25 \\
2 & Pendidika & Diploma 1 (D1) & 20 & 33,90 \\
3 & n & Diploma 2 (D2) & 1 & 1,69 \\
4 & Terakhir & Diploma 3 (D3) & 26 & 44,07 \\
$\mathbf{5}$ & & Sarjana (S1) & 3 & 5,09 \\
& & Total & $\mathbf{5 9}$ & $\mathbf{1 0 0}$ \\
\hline
\end{tabular}

Sumber: Data primer diolah, 2020

Hasil rekapitulasi uji validitas dan reliabilitas penelitian ini terdapat pada Tabel 4. Hasil uji validitas pada Tabel 4 diatas menunjukkan bahwa seluruh variabel memiliki nilai koefisien korelasi dengan skor total seluruh item pernyataan lebih besar dari 0,30. Hal ini menunjukkan bahwa butir-butir pernyataan dalam instrument penelitian tersebut valid. Hasil juga menunjukkan bahwa seluruh instrumen penelitian memiliki koefisien Cronbach's Alpha lebih dari 0,60. Hal ini dapat dikatakan bahwa semua instrumen reliabel sehingga dapat digunakan untuk melakukan penelitian.

Tabel 6 menunjukkan bahwa rata-rata skor dari 3 pernyataan mengenai turnover intention yaitu sebesar 3,84 yang berada di kisaran 3,41 - 4,20 yang berarti niat karyawan untuk meninggalkan perusahaan (turnover intention) tinggi di Wyndham Taman Sari Jivva Resort Bali. Jawaban responden tertinggi pada pernyataan Y1 "Saya berkeinginan untuk mencari perusahaan lain sesuai dengan keahlian" dan Y3 "Saya berkeinginan untuk meningkatkan jenjang karir diperusahaan lain." Hal ini mengindikasikan bahwa karyawan memiliki keinginan 
mencari pekerjaan lain sesuai dengan keahlian di perusahaan yang berbeda dan meningkatkan karir di perusahaan lain.

Tabel 5.

Hasil Uji Validitas dan Reliabilitas

\begin{tabular}{|c|c|c|c|c|c|}
\hline Variabel & Indikator & $\begin{array}{c}\text { Koefisien } \\
\text { Korelasi } \\
\end{array}$ & $\begin{array}{c}\text { Sig. } \\
\text { (2tailed) }\end{array}$ & $\begin{array}{c}\text { Cronbach's } \\
\text { Alpha }\end{array}$ & Keterangan \\
\hline \multirow{5}{*}{ Stres Kerja $(\mathrm{X})$} & $\mathrm{X}_{1}$ & 0,818 & 0,000 & \multirow{6}{*}{0815} & \multirow{6}{*}{$\begin{array}{l}\text { Valid dan } \\
\text { Reliabel }\end{array}$} \\
\hline & $\mathrm{X}_{2}$ & 0,896 & 0,000 & & \\
\hline & $\mathrm{X}_{3}$ & 0,843 & 0,000 & & \\
\hline & $\mathrm{X}_{4}$ & 0,865 & 0,000 & & \\
\hline & $\mathrm{X}_{5}$ & 0,841 & 0,000 & & \\
\hline & $\mathrm{X}_{6}$ & 0,894 & 0,000 & & \\
\hline \multirow{9}{*}{$\begin{array}{c}\text { Komitmen } \\
\text { organisasional } \\
(\mathrm{Z})\end{array}$} & $\mathrm{Z}_{1}$ & 0,903 & 0,000 & \multirow{9}{*}{0,926} & \multirow{9}{*}{$\begin{array}{l}\text { Valid dan } \\
\text { Reliabel }\end{array}$} \\
\hline & $Z_{2}$ & 0,825 & 0,000 & & \\
\hline & $Z_{3}$ & 0,829 & 0,000 & & \\
\hline & $\mathrm{Z}_{4}$ & 0,829 & 0,000 & & \\
\hline & $\mathrm{Z}_{5}$ & 0,905 & 0,000 & & \\
\hline & $\mathrm{Z}_{6}$ & 0,844 & 0,000 & & \\
\hline & $\mathrm{Z}_{7}$ & 0,921 & 0,000 & & \\
\hline & $\mathrm{Z}_{8}$ & 0,776 & 0,000 & & \\
\hline & $\mathrm{Z}_{9}$ & 0,927 & 0,000 & & \\
\hline \multirow{3}{*}{$\begin{array}{c}\text { Turnover } \\
\text { intention }(\mathrm{Y})\end{array}$} & $Y_{1}$ & 0,861 & 0,000 & \multirow{3}{*}{0,776} & \multirow{3}{*}{$\begin{array}{l}\text { Valid dan } \\
\text { Reliabel }\end{array}$} \\
\hline & $\mathrm{Y}_{2}$ & 0,896 & 0,000 & & \\
\hline & $\mathrm{Y}_{3}$ & 0,785 & 0,000 & & \\
\hline
\end{tabular}

Sumber: Data diolah, 2020

Jawaban responden mengenai masing-masing pernyataan pada variabel Turnover Intention adalah sebagai berikut:

Tabel 6.

Deskripsi Variabel Turnover Intention(Y)

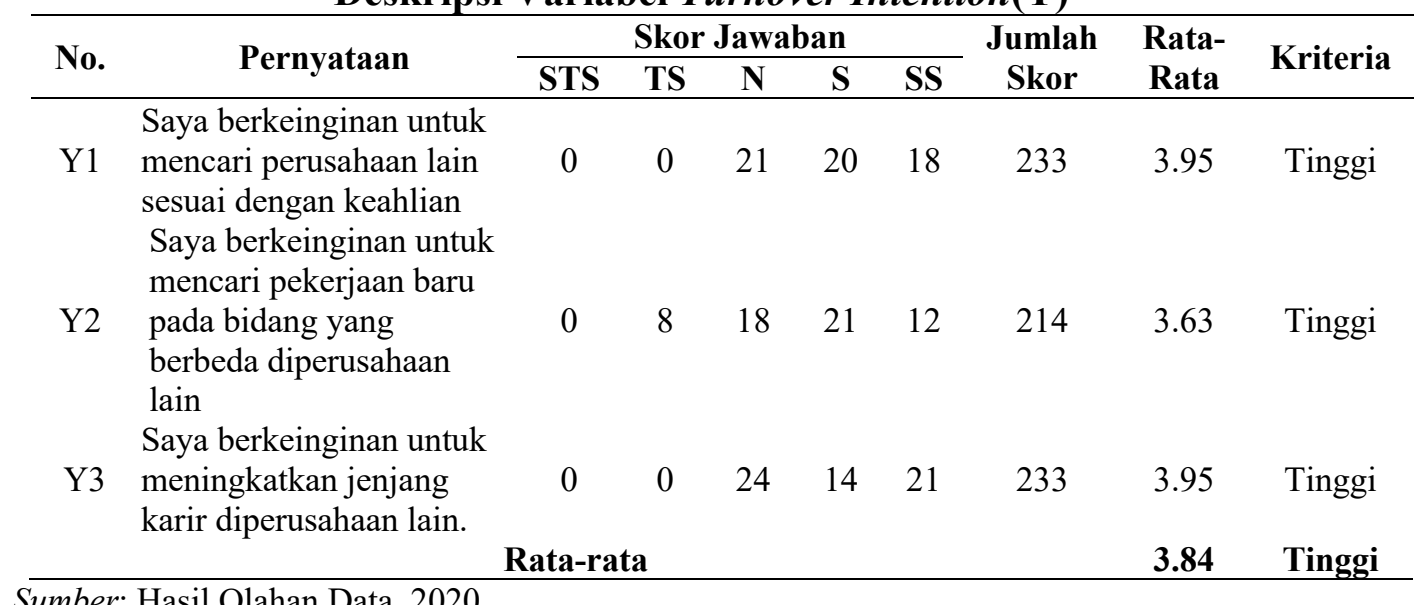

Jawaban responden mengenai masing-masing pernyataan pada variabel stres kerja secara rinci dapat dilihat pada Tabel 6. berikut. 
Tabel 7.

Deskripsi Variabel Stres Kerja (X)

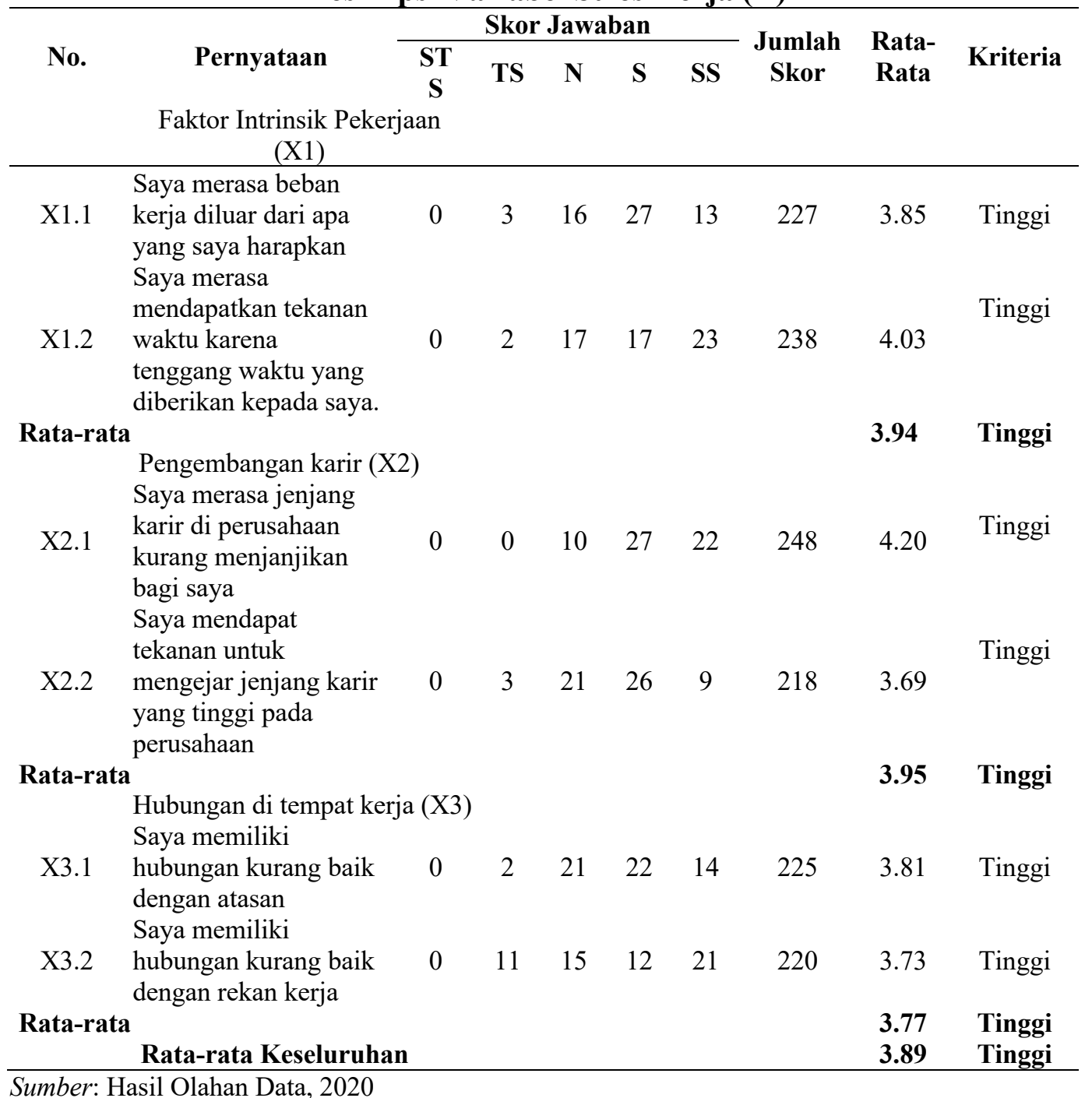

Tabel 7. menunjukkan bahwa rata-rata skor dari 6 pernyataan mengenai stres kerja yaitu sebesar 3,89 yang berada di kisaran 3,41 - 4,20 yang berarti stres kerja di Wyndham Taman Sari Jivva Resort Bali Tinggi. Distribusi jawaban responden terhadap stres kerja dengan nilai rata-rata tertinggi pada dimensi pengembangan karir X2.1 dimana berisikan pernyataan "Saya merasa jenjang karir di perusahaan kurang menjanjikan bagi saya". Hal ini menunjukkan bahwa karyawan mengalami stres kerja akibat dari jenjang karir diperusahaan dirasa kurang menjanjikan perusahaan sehingga karyawan memiliki keinginan untuk meninggalkan perusahaan.

Jawaban responden mengenai masing-masing pernyataan pada variabel komitemen organisasional secara rinci dapat dilihat pada Tabel 8 . 
Tabel 8.

Deskripsi Variabel Komitmen Organisasional (Z)

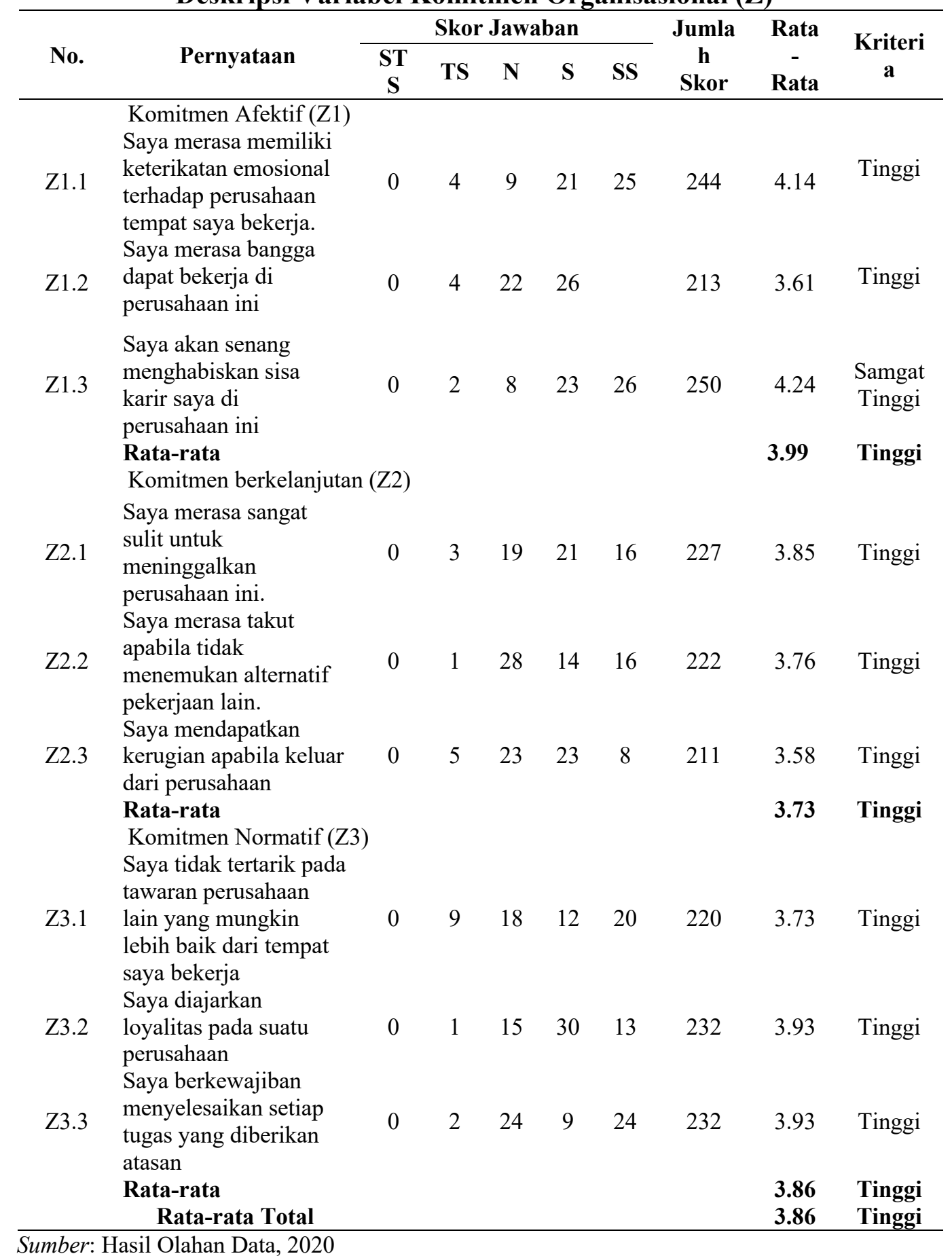

Tabel 8. menunjukkan bahwa rata-rata skor dari 9 pernyataan mengenai komitmen organisasional sebesar 3,86 yang berada di kisaran 3,41 - 4,20 yang berarti komitmen organisasional di Wyndham Taman Sari Jivva Resort Tinggi. 
Distribusi jawaban responden terhadap komitmen organisasional dengan nilai ratarata tertinggi pada pernyataan Z1.3 "Saya akan senang menghabiskan sisa karir saya di perusahaan ini". Terindikasi dalam pernyataan tersebut bahwa karyawan merasa senang apabila dapat menghabiskan sisa karir di Wyndham Taman Sari Jivva Resort Bali.

Tabel 9.

Hasil Analisis Jalur 1

\begin{tabular}{lcrrrr}
\hline \multirow{2}{*}{ Variabel } & \multicolumn{7}{c}{ Unstandardized Coefficients } & \multicolumn{2}{c}{$\begin{array}{c}\text { Standardized } \\
\text { Coefficients }\end{array}$} & & \\
\cline { 2 - 3 } & \multicolumn{1}{c}{ B } & Std. Error & Beta & T & Sig. \\
\hline (Constant) & 7,121 & 0,365 & & 19,488 & 0,000 \\
Stres kerja & $-0,838$ & 0,093 & $-0,767$ & $-9,035$ & 0,000 \\
Dependen variabel & Komitmen organisasional & & & \\
R Square & 0,589 & & & \\
Adjusted R Square & 0,582 & & & \\
F Statistik & 81,638 & & & \\
Signifikansi Uji F & 0,000 & & & \\
\end{tabular}

Sumber: Data diolah, 2020

Nilai koefisien regresi variabel Stres kerja bernilai negatif dengan nilai signifikansi uji t kurang dari 0,05. Hal ini menunjukkan bahwa variabel Stres kerja memiliki pengaruh negatif yang signifikan terhadap variabel Komitmen organisasional. Besarnya pengaruh variabel bebas terhadap variabel terikat yang ditunjukkan oleh nilai determinasi total (R Square) sebesar 0,589 mempunyai arti bahwa sebesar 58,9 persen variasi Komitmen organisasional dipengaruhi oleh variasi Stres kerja, sedangkan sisanya sebesar 41,1 persen dijelaskan oleh faktor lain yang tidak dimasukkan ke dalam model.

Tabel 10.

Hasil Analisis Jalur 2

\begin{tabular}{|c|c|c|c|c|c|}
\hline \multirow[t]{2}{*}{ Variabel } & \multicolumn{2}{|c|}{$\begin{array}{c}\text { Unstandardized } \\
\text { Coefficients } \\
\end{array}$} & \multirow{2}{*}{$\begin{array}{c}\begin{array}{c}\text { Standardize } \\
\text { d } \\
\text { Coefficients }\end{array} \\
\text { Beta } \\
\end{array}$} & \multirow[b]{2}{*}{$\mathbf{T}$} & \multirow[b]{2}{*}{ Sig. } \\
\hline & B & Std. Error & & & \\
\hline (Constant) & 4,417 & 0,685 & & 6,445 & $\begin{array}{r}0,00 \\
0\end{array}$ \\
\hline Stres kerja & 0,452 & 0,098 & 0,394 & 4,609 & $\begin{array}{r}0,00 \\
0\end{array}$ \\
\hline $\begin{array}{l}\text { Komitmen } \\
\text { organisasional }\end{array}$ & $-0,603$ & 0,090 & $-0,574$ & 6,723 & $\begin{array}{r}0,00 \\
0\end{array}$ \\
\hline Dependen variabel & & Turnover intention & & & \\
\hline R Square & & 0,832 & & & \\
\hline Adjusted R Square & & 0,826 & & & \\
\hline F Statistik & & 138,644 & & & \\
\hline Signifikansi Uji F & & 0,000 & & & \\
\hline
\end{tabular}


Nilai signifikansi masing-masing variabel bebas kurang dari 0,050. Hal ini menunjukkan bahwa semua variabel bebas memiliki pengaruh yang signifikan terhadap variabel terikat. Besarnya pengaruh variabel bebas terhadap variabel terikat yang ditunjukkan oleh nilai determinasi total (R Square) sebesar 0,832 mempunyai arti bahwa sebesar 83,2 persen variasi Turnover intention dipengaruhi oleh variasi Stres kerja dan Komitmen organisasional, sedangkan sisanya sebesar 16,8 persen dijelaskan oleh faktor lain yang tidak dimasukkan ke dalam model.

Berdasarkan model substruktur 1 dan substruktur 2, maka dapat disusun model diagram jalur akhir. Sebelum menyusun model diagram jalur akhir, terlebih dahulu dihitung nilai standar eror sebagai berikut :

$$
\begin{aligned}
& \mathrm{Pe}_{1}=\sqrt{1-R_{1}{ }^{2}}=\sqrt{1-0,589}=0,641 \\
& \mathrm{Pe}_{2}=\sqrt{1-R_{2}^{2}}=\sqrt{1-0,832}=0,409
\end{aligned}
$$

Berdasarkan perhitungan pengaruh error (Pei), didapatkan hasil pengaruh error $\left(\mathrm{Pe}_{1}\right)$ sebesar 0,641 dan pengaruh error $\left(\mathrm{Pe}_{2}\right)$ sebesar 0,409. Hasil koefisien determinasi total adalah sebagai berikut :

$$
\begin{aligned}
\mathrm{R}_{\mathrm{m}}{ }_{\mathrm{m}} & =1-\left(\mathrm{Pe}_{1}\right)^{2}\left(\mathrm{Pe}_{2}\right)^{2} \\
& =1-(0,641)^{2}(0,409)^{2}=0,932
\end{aligned}
$$

Nilai determinasi total sebesar 0,932 mempunyai arti bahwa sebesar 93,2 persen variasi Turnover intention pada karyawan Wyndham Taman Sari Jivva Resort Bali dipengaruhi oleh variasi Stres kerja dan Komitmen organisasional, sedangkan sisanya sebesar 6,8 persen djelaskan oleh faktor lain yang tidak dimasukkan ke dalam model

Hasil koefisien jalur pada hipotesis penelitian dapat digambarkan pada Gambar 2. berikut :

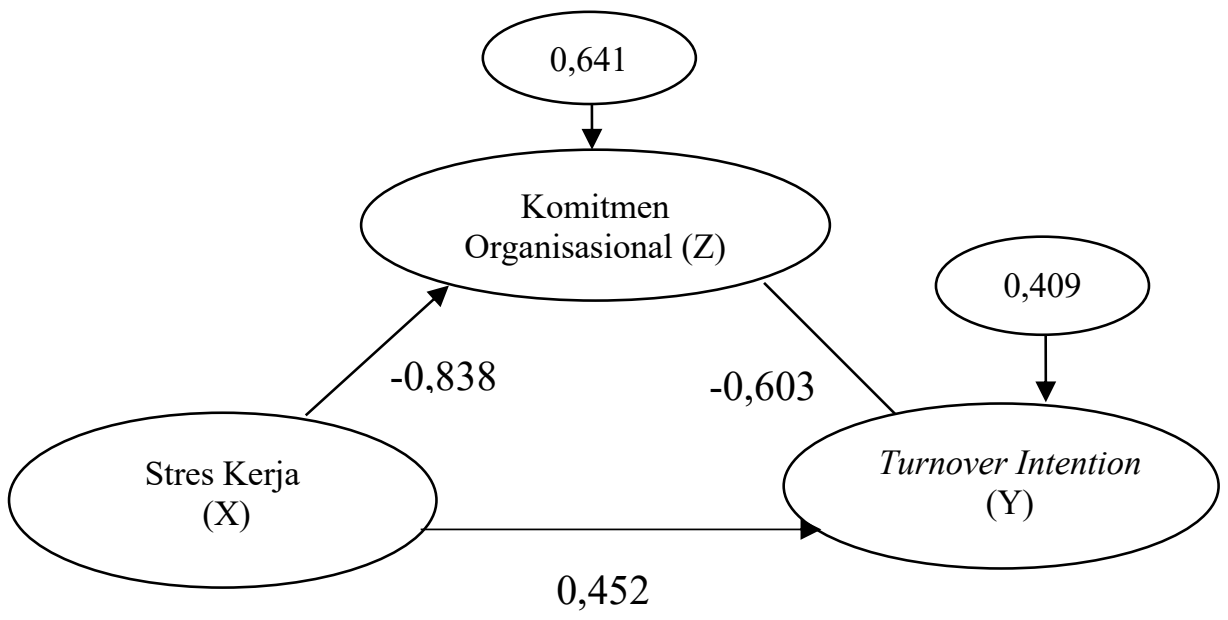

Gambar 2. Validasi Model Diagram Jalur Akhir

Sumber : Data diolah, 2020 
Berdasarkan diagram jalur pada Gambar 2, maka dapat dihitung besarnya pengaruh langsung dan pengaruh tidak langsung serta pengaruh total antar variabel. Perhitungan pengaruh antar variabel dirangkum dalam Tabel 10.

Tabel 11.

Pengaruh Langsung, Tidak Langsung serta Pengaruh Total Variabel

\begin{tabular}{cccc}
\hline $\begin{array}{c}\text { Pengaruh } \\
\text { Variabel }\end{array}$ & $\begin{array}{c}\text { Pengaruh } \\
\text { Langsung }\end{array}$ & $\begin{array}{c}\text { Pengaruh Tidak Langsung Melalui } \\
\text { Komitmen organisasional } \\
(\mathbf{Y 1})(\boldsymbol{\beta 1} \mathbf{x} \boldsymbol{\beta 3})\end{array}$ & Pengaruh Total \\
\hline $\mathrm{X} \rightarrow \mathrm{Z}$ & $-0,838$ & - & $-0,838$ \\
$\mathrm{X} \rightarrow \mathrm{Y}$ & 0,452 & 0,505 & 0,957 \\
$\mathrm{Z} \rightarrow \mathrm{Y}$ & $-0,603$ & - & $-0,603$ \\
\hline
\end{tabular}

Sumber : Data primer diolah, 2020

Pengujian pengaruh tidak langsung variabel Stres kerja $(X)$ terhadap variabel Turnover intention (Y) melalui variabel komitmen organisasional (Z), dihitung dengan rumus sebagai berikut :

$$
\begin{aligned}
& S_{b 1 b 3}=\sqrt{(-0,603)^{2}(0,093)^{2}+(0,838)^{2}(0,090)^{2}+(0,093)^{2}(0,090)^{2}} \\
& S_{b 1 b 3}=0,094356
\end{aligned}
$$

Untuk menguji signifikansi pengaruh tidak langsung maka menghitung nilai $\mathrm{z}$ dari koefisien $\mathrm{ab}$ dengan rumus sebagai berikut

$\mathrm{Z}=\frac{b 1 b 3}{S b 1 b 3}$

$Z=\frac{(0,838)(0,603)}{0,094356}=5,3554$

Nilai Z hitung sebesar 5,3554 > 1,96. Artinya Komitmen organisasional (Z) merupakan variabel yang memediasi Stres kerja (X) terhadap Turnover intention (Y) pada karyawan Wyndham Taman Sari Jivva Resort Bali. Hasil penelitian ini sesuai dengan hipotesis $4\left(\mathrm{H}_{4}\right)$ yang diajukan dan sesuai dengan penelitian yang dilakukan oleh Akehurst et al, (2009), Rismawan et al, (2015), Irwanto dkk, (2016), Putra dan Ardana (2018), Pranata dan Netra (2019) yang menyatakan bahwa stres kerja berpengaruh negatif dan signifikan terhadap turnover intention melalui mediasi komitmen organisasional pada karyawan Wyndham Taman Sari Jivva Resort Bali

Hasil analisis pengaruh Stres kerja terhadap Komitmen organisasional diperoleh nilai signifikansi sebesar 0,000 dengan nilai koefisien regresi negatif sebesar -0,838. Nilai Signifikansi $0,000<0,05$ mengindikasikan bahwa $\mathrm{H}_{1}$ diterima. Hasil ini mempunyai arti bahwa Stres kerja berpengaruh negatif dan signifikan terhadap Komitmen organisasional Karyawan Wyndham Taman Sari Jivva Resort Bali. Hal ini menyatakan bahwa semakin tinggi tingkat stres kerja karyawan maka komitmen organisasional karyawan di Wyndham Taman Sari Jivva Resort Bali akan menurun. Hasil penelitian ini sesuai dengan hipotesis satu $\left(\mathrm{H}_{1}\right)$ yang diajukan dan sesuai dengan penelitian yang dilakukan oleh Velnampy dan Aravinthan (2013), Putra dan Ardana (2018), Rismawan dkk. (2015), Irwanto dkk. (2016), Pranata dan Netra (2019), Harun et al. (2017) yang menyatakan bahwa stres kerja memiliki pengaruh negatif dan signifikan terhadap komitmen organisasional. 
Hasil analisis pengaruh Komitmen organisasional terhadap Turnover intention diperoleh nilai signifikansi sebesar 0,000 dengan nilai koefisien regresi negatif sebesar $-0,603$. Nilai Signifikansi $0,000<0,05$ mengindikasikan bahwa $\mathrm{H}_{2}$ diterima. Hasil ini mempunyai arti bahwa Komitmen organisasional berpengaruh negatif dan signifikan terhadap Turnover intention Karyawan Wyndham Taman Sari Jivva Resort Bali. Hal ini menyatakan bahwa semakin tinggi komitmen organisasional yang dimiliki karyawan maka akan menurunkan turnover intention di Wyndham Taman Sari Jivva Resort Bali. Hasil penelitian ini sesuai dengan hipotesis dua $\left(\mathrm{H}_{2}\right)$ yang diajukan dan sesuai dengan penelitian yang dilakukan oleh Pranata dan Netra (2019), Matti (2014), Saqib et al. (2014), Johartono dan Widuri (2014), Putra dan Wibawa (2014) yang menyatakan bahwa komitmen organisasional memiliki pengaruh negatif dan signifikan terhadap turnover intention.

Hasil analisis pengaruh Stres kerja terhadap Turnover intention diperoleh nilai signifikansi sebesar 0,000 dengan nilai koefisien regresi positif sebesar 0,452. Nilai Signifikansi $0,000<0,05$ mengindikasikan bahwa dan $\mathrm{H}_{3}$ diterima. Hasil ini mempunyai arti bahwa Stres kerja berpengaruh positif dan signifikan terhadap Turnover intention Karyawan Wyndham Taman Sari Jivva Resort Bali. Hal ini menyatakan bahwa semakin tinggi stres kerja karyawan di Wyndham Taman Sari Jivva Resort Bali maka tingkat turnover intention akan meningkat. Hasil penelitian ini sesuai dengan hipotesis tiga $\left(\mathrm{H}_{3}\right)$ yang diajukan dan sesuai dengan penelitian yang dilakukan oleh Parvaiz et al. (2015), Rai (2015), Mitchell et al. (2014), Ketabchi dan Hazraty (2015), Siddiqui dan Jamil (2015), Yuda dan Ardana (2017) yang menyatakan stres kerja berpengaruh positif dan signifikan terhadap turnover intention.

Implikasi Teoritis penelitian ini menunjukan bahwa stress kerja memiliki pengaruh positif dan signifikan terhadap turnover intention, dan komitmen organisasional berpangaruh negatif dan signifikan terhadap turnover intention. Dengan demikian, hasil penelitian ini memberikan dukungan empiris dan dapat dinyatakan memperkuat hasil-hasil studi terdahulu.

Implikasi praktis dari penelitian ini diharapkan bagi pemimpin di Wyndham Taman Sari Jivva Resort Bali dapat lebih memperhatikan stres kerja, komitmen organisasional yang mempengaruhi turnover intention ditunjukkan dengan nilai determinasi total sebesar 0,932 mempunyai arti bahwa sebesar 93,2 persen sedangkan sisanya sebesar 6,8 persen djelaskan oleh faktor lain yang tidak dimasukkan ke dalam model ini

\section{SIMPULAN}

Simpulan pertama dalam penelitian ini yaitu Stres kerja memiliki pengaruh negatif dan signifikan terhadap komitmen organisasional. Kedua, Komitmen organiasasional memiliki pengaruh negatif dan signifikan terhadap turnover intention. Ketiga, Stres kerja memiliki pengaruh positif dan signifikan terhadap turnover intention. Keempat, Komitmen organisasional merupakan variabel yang memediasi Stres kerja terhadap Turnover intention pada karyawan Wyndham 
Taman Sari Jivva Resort Bali atau dengan kata lain Stres kerja berpengaruh secara tidak langsung terhadap Turnover intention melalui komitmen organisasional.

Berdasarkan hasil analisis maka disarankan bagi Pihak manajemen dan HRD Wyndham Taman Sari Jivva Resort Bali sebaiknya lebih memperhatikan turnover intention yang terjadi di perusahaan terutama pada karyawan yang ingin meninggalkan perusahaan karena ada perusahaan yang lebih baik dan perusahaan lain yang memberikan jenjang karir lebih baik dibandingkan perusahaan tempat karyawan tersebut bekerja saat ini. Kemudian Sebaiknya manajemen dan HRD memberikan beban kerja sesuai dengan kemampuan dan jabatan dari setiap karyawan. Beban kerja yang sesuai dengan kemampuan dan jabatan dapat menurunkan stres kerja karyawan karena karyawan tersebut telah menguasai tugastugas yang akan diberikan selama bekerja di Wyndham Taman Sari Jivva Resort Bali.

\section{REFERENSI}

Addae, H, M., Boso, N., \& Ofori, D. (2012). Perceptions of Absence Legitimacy: Effects of Job Stress, Organizational Commitment and Perceived Organizational Support. Pacific Journal of Business Research, 8(2), 1-19.

Akehurst, G., Comeche, J. M., \& Galindo, M. A. (2009). Job Satisfaction and Commitment in the Entrepreneurial SME. Small Business Economics, 32(3), 277-289.

Clayton, B., \& Hutchinson, M. R. (2002). Organisational Commitment of Accountants in Australia and South Africa. South African Journal of Accounting Research, 16(1), 1-17.

Damayanthi, A. A. S. S., \& Sintaasih, D. K. (2016). Pengaruh Keselamatan Dan Kesehatan Kerja Terhadap Komitmen Organisasional Dan Kinerja Karyawan. E-Jurnal Manajemen Udayana, 14(2), 1-20.

Fahmi, I. (2016). Manajemen Sumber Daya Manusia. Yogyakarta: Alfabeta.

Gillies, D. (1989). Manajemen Keperawatan: Suatu Pendekatan Sistem (Edisi 2). Illioni: WB Saunders Company.

Harun, H., Salleh, R., Memon, M. A., Baharom, M. N. R., \& Abdullah, A. (2017). Job Satisfaction, Organizational Commitment and Stress among Offshore Oil and Gas Platform Employees. Asian Social Science, 10(11), 28-32. Retrieved from https://doi.org/10.5539/ass.v10n11p28\%0A\%0A

Hlatywayo, C. K., Mlanga, T. S., \& Zingwe, T. (2014). Precursors of Emotional Stability, Stress and Work-Family Conflict Among Female Bank Employees. International Business \& Economics Research Journal, 13(4), 861-866.

Irwanto, Riana, I. G., \& Yasa, N. N. K. (2016). Peran Komitmen Organisasional 
Memediasi Pengaruh Stres Kerja Dan Kepuasan Kerja Terhadap Intensi Keluar. E-Jurnal Ekonomi Dan Bisnis Universitas Udayana, 5(9), 28912910.

Johartono, \& Widuri, R. (2014). Analisa Pengaruh Stres Kerja, Kepuasan Kerja, Budaya Organisasi dan Komitmen Organisasi Terhadap Turnover intention karywan Kantor Konsultan pajak di Surabaya. Journal of Tax and Accounting Review, 3(2), 223-241.

Ketabchi, H., \& Hazraty, M. (2015). Examining the Relationship between Job Stress and Turnover Tendency with Mediating Role of Job Satisfaction among the Employees of Alzahra Hospital in Rasht. Jurnal UMP Social Sciences and Technology Management, 3(3), 842-846.

Lee, H. . (2000). An Empirical Study of Organizational Justice as a Mediator of the Relationships Among Leader-Member Exchange and Job Satisfaction, Organizational Commitment, and Turnover Intentions in the Lodging Industry. Journal of Polytechnic Institute and State University, 8(3), 468478.

Mathieu, J. E., \& Zajac, D. M. (1990). A Review and Meta-Analysis of the Antecedents, Correlates, and Consequences of Organisational Commitment and Satisfaction. Psychological Bulletin, 108(2), 171-194.

Matti, V. (2014). Organizational Reform in Hierarchical Frontline Organization Tracking Changes in Stress and Turnover Intention During Finish Police Reform Years. An International Journal of Police Strategies \& Management, 37(4), 850-874.

Michael, O., \& Court, D. (2009). Job Stress and Organizational Commitment Among Mentoring Coordinators. International Journal of Educational Management, 23(3), 26-54.

Ming-Shiun, C., \& Shin-Lung, H. (2019). The Relationship Among Job Stress, Well-Being, Organizational Commitment and Turnover Intention - a Case Study of Officers and Sergeants. Commerce \& Management Quarterly, 20(2), 157-179.

Mitchell, O., Mackenzie, D. L., Styve, G. J., \& Gover, A. (2014). The Impact of Individual, Organizational and Environmental Attributes on Voluntary Turnover Among Juvenile Correctional Staf Members. Justice Quarterly: Academy of Criminal Justice Science, 17(2), 332-357.

Parvaiz, L., Saba, B., Ambar, K., \& Yasir, A. F. (2015). Impact of Stressors (Role Conflict, Role Overload, Leadership Support and Organizational Politics) on Job Stress and its Subsequent Impact on Turnover Intention. International Journal of Business and Management Invention, 4(10), 52-63. 
Pranata, G. D., \& Netra, I. G. S. K. (2019). Pengaruh Stres Kerja Terhadap Turnover Intention Melalui Mediasi Komitmen Organisasional Pada Restoran Queen's Tandoor Seminyak. E-Jurnal Ekonomi Dan Bisnis Universitas Udayana, 8(6), 3531-3559.

Putra, E. M., \& Wibawa, M. A. (2014). Pengaruh Kepuasan Kerja Terhadap Turnover Intention dengan Komitmen Organisasi sebagai Variabel Intervening pada PT. Auto Bagus Rent Car Bali. E-Jurnal Manajemen Unud, 4(4), 1100-1118.

Putra, I. G. Y., \& Ardana, I. K. (2018). Peran Komitmen Organisasional Dalam Memediasi Pengaruh Stres Kerja Terhadap Turnover Intention Di Bali Rochmat Jaya. E-Jurnal Manajemen Unud, 5(12), 6562-6590.

Putri Rarasanti, I. A., \& Suana, I. W. (2016). Pengaruh Job Embeddedness, Kepuasan Kerja, dan Komitmen Organisasional terhadap Turnover Intention Karyawan. E-Jurnal Manajemen Unud, 5(7), 4690-4718. Retrieved from https://media.neliti.com/media/publications/249086-pengaruh-jobembeddedness-kepuasan-kerja-79a811ef.pdf

Rai, G. S. (2015). Turnover Intention among Long-term Care Staff: Three Possible Culprits. International Journal of Business and Social Science, 6(8), 1-9.

Rismawan, P. A. E., Supartha, W. G., \& Yasa, N. N. K. (2015). Peran Mediasi Komitmen Organisasional pada Pengaruh Stres Kerja dan Kepuasan Kerja terhadap Intensi Keluar Karyawan. E-Jurnal Ekonomi Dan Bisnis Universitas Udayana, 8(3), 424-441.

Robbins, S. P., \& Judge, T. A. (2015). Perilaku Organisasi (Edisi 16). Jakarta Selatan: Salemba Empat.

Salleh, A. L., Bakar, R. A., \& Keong, W. K. (2008). How Detrimental is Job Stress?: A Case Study Of Executives in the Malaysian Furniture Industry. International Review of Business Research Papers, 4(5), 78-111.

Saqib, M. K., Kundi, G. M., Shadiullah, K., Irfanullah, K., Hamid, K., \& Naseem, B. Y. (2014). The Cause \& Effect and Correlation Between Job Satisfaction and Organizational Commitment on Intention to Leave Among the Academicians in Higher Educational Institutions of Khyber Pakhtunkhwa, Pakistan. International Journal of Academic Research in Business and Social Sciences, 4(2), 34-75.

Serinikli, N. (2019). The Mediating Role of Organizational Commitment in the Effect of Job Stress on Turnover Intention. Business and Economics Research Journal, 10(4), 915-928.

Shaleh, M. (2018). Komitmen Organisasi terhadap Kinerja Pegawai. Makasar: 
Aksara Timur.

Shih-Tse Wang, E. (2014). The Effects of Relationship Bonds on Emotional Exhaustion and Turnover Intentions in Frontline Employees. Journal of Services Marketing, 28(4), 319-330.

Siddiqui, A. A., \& Jamil, R. A. (2015). Antecedents of Employees Turnover Intentions: Evidence from Private Educational Institutions. American Journal of Economics and Business Administration, 7(4), 160-165.

Suhada, A., Marnis, \& Hamid, L. (2015). Pengaruh Konflik Kerja dan Stres terhadap Komitmen Organisasi pada PT United Tractors Cabang Pekan Baru. Jom Fekon, 2(1), 1-15. Retrieved from https://jom.unri.ac.id/index.php/JOMFEKON/article/view/7999

Taing, M., Granger, B., Groff, K., Jackson, E., \& Johnson, R. (2011). The Multidimensional Nature of Continuance Commitment: Commitment Owing to Economic Exchanges Versus Lack of Employment Alternatives. Journal of Business \& Psychology, 26(4), 269-284.

Velnampy, T., \& Aravinthan, S. A. (2013). Occupational Stress and Organizational Commitment in Private Banks: A Sri Lankan Experience. European Journal of Business and Management, 5(7), 78-99.

Widjaja, D. C., Margarita, F., \& Fenny, K. D. W. (2008). Persepsi Employee Empowerment Terhadap Employee Turnover Intention. Jurnal Manajemen Perhotelan, 4(2), 72-84.

Widodo, S. E. (2015). Manajemen Pengembangan Sumber Daya Manusia. Yogyakarta: Pustaka Pelajar.

Yuda, I. B. D. P., \& Ardana, I. K. (2017). Pengaruh Kepuasan Kerja dan Stres Kerja terhadap Turnover Intention pada Karyawan Hotel Holiday Inn Express. EJurnal Manajemen Unud, 6(10), 5319-5347. 